\title{
Local analysis of airflow distribution in open concept passive houses
}

\author{
Doru Daniel Sabie ${ }^{1 *}$,Viorel Fatu, and Adrian-Gabriel Ghiaus ${ }^{1}$ \\ ${ }^{1}$ Technical University of Civil Engineering of Bucharest, 021414 Bucharest, Romania
}

\begin{abstract}
This paper presents the analysis of local air currents distribution near the inlet and outlet openings in a living room of study a pre-certified passive house located in Cluj-Napoca by CFD numerical simulation. The simulation domain is represented by an open space concept, comprising the living room and the kitchen, situated at the ground floor of the building. The used heat recovery ventilation system controls both the supply of fresh air through the inlet grilles, located on the floor of the living room and the extraction of exhaust air through outlet grilles with circular cross section positioned on the other side, in the kitchen's ceiling. An area of interest has been selected to define the simulation domain. Numerical modeling has been carried out by means of a commercial software based on the finite element method to simulate a series of interconnected phenomena encountered in the analysed application. The dry air was chosen as working agent for the field of simulation/calculation. Its thermo-physical properties were selected from the program database. No slip limit conditions have been imposed for all the delimiting surfaces of the computational field. Inlet and outlet grilles were considered open borders for circulated air volume flow in three distinct analysed cases. For the simulation of the flow of the working fluid through the computational domain, the following simplifying assumptions were considered: stationary regime, incompressible fluid, constant temperature, isothermal jet, adiabatic system, without internal heat sources, without taking into account the mass forces. The discretization of the simulation domain was divided into an optimal number of finite variable elements, with a greater density near the border areas. The results of air currents distribution in the vicinity of grid areas, for inlet fresh air and outlet exhaust air, was done by analyzing the current lines, the velocity vectors and the velocity contours.
\end{abstract}

\section{Introduction}

The need to breathe fresh air and to benefit from ventilation to ensure proper comfort is constantly felt, no matter the weather or the season.

The nature and amount of harmful rebates, their propagation mode, the building system of the enclosures, the values at which indoor air parameters are prescribed for comfort or technological reasons, the admissible limits to which the concentrations of the various harmful substances must be reduced, to which many or with significant economic considerations, have led to the use of a wide variety of ventilation and air conditioning installations.

In addition to chemical composition and air purity, the environmental quality of closed environments is tight and appreciated by the value of thermal comfort parameters, ensured by the quality and efficiency of the adopted ventilation system.

In the card of the European research programs and projects promoted, developed and coordinated by Passive House Institute (PHI) [1,2,3] regarding the ventilation systems suitable for passive houses, in order to achieve efficient energy ventilation, it was demonstrated that a controlled ventilation strategy of airflows circulation has to be done.

Fresh air must be provided in the "dry" rooms such as living, working and sleeping rooms, and extracted from the "wet" rooms, such as kitchens, bathrooms and hallways $[4,8]$.

Taking into account the design and construction requirements for a very good insulation and sealing of the building anvelope elements of passive houses, the ventilation system must ensure an indoor air refresh rate so as to satisfy two conditions: to provide a high level of indoor comfort and to minimize heat losses $[5,6,7]$.

The paper seeks to analyze how the presence of furniture in the simulation field could significantly influence the behavior of air.

This paper presents the results obtained by numerical modeling and simulation, assisted by the specialized software COMSOL Multiphisycs [9] on the local analysis of the qualitative and quantitative distribution of air currents in the areas near the air inlet and outlet grilles of a pre-tested passive house.

*Email: 03dany75@gmail.com 


\section{Materials and methods}

\subsection{Building description and performance}

The building analyzed, located in Cluj-Napoca, is an individual dwelling with the useful surface $S_{u}=276 \mathrm{~m}^{2}$. In terms of constructive aspects, although concrete structure was initially provided in draft design, finally a constructive solution made of polystyrene formwork filled with monolith concrete was adopted.

The large glazed surfaces, which are mostly oriented to the south, ensure both the required solar input and natural light, while reducing visual barrier between inside and outside. The reduced number of gaps on the main façade from the north reduces heat loss and gives privacy to the occupants.

In the cross section of the building, in Figure 1, it can be seen the characteristic parameters of the building envelope components [10], as follows:

- exterior walls: $U_{\text {anv, opaque }}=0,128 \mathrm{~W} / \mathrm{m}^{2} \mathrm{~K}$,

- glazing: $\mathrm{U}_{\text {glazing }}=0,51 \mathrm{~W} / \mathrm{m}^{2} \mathrm{~K}$,

- frame: $\mathrm{U}_{\text {frame }}=0,79 \mathrm{~W} / \mathrm{m}^{2} \mathrm{~K}$,

- flooring: $\mathrm{U}_{\text {floor }}=0,125 \mathrm{~W} / \mathrm{m}^{2} \mathrm{~K}$,

- roof: $\mathrm{U}_{\text {roof }}=0,1 \mathrm{~W} / \mathrm{m}^{2} \mathrm{~K}$.

In order to establish the energy performance of the building, preliminary tests by PHI (Passive House Institute) experts showed that the annual energy demand for heating is $12 \mathrm{kWh} / \mathrm{m}^{2}$, and the required annual primary energy is $58 \mathrm{kWh} / \mathrm{m}^{2}$.

During the cold season, to cover peak consumption, the heating needs of the passive house will be secured by a fireplace in the living room. It incorporates an ignitubular heat exchanger that provides heat load for domestic hot water during winter and during periods of inactivity of solar panels placed on the green roof. Storage of hot water is done in two underground storage tanks.

Centralized ventilation of the building is provided by a ventilation system with heat recovery, which will distribute at floor level, Figure 2, the fresh air pre-cooled in summer and preheated in winter by means of a closedloop geothermal collector.

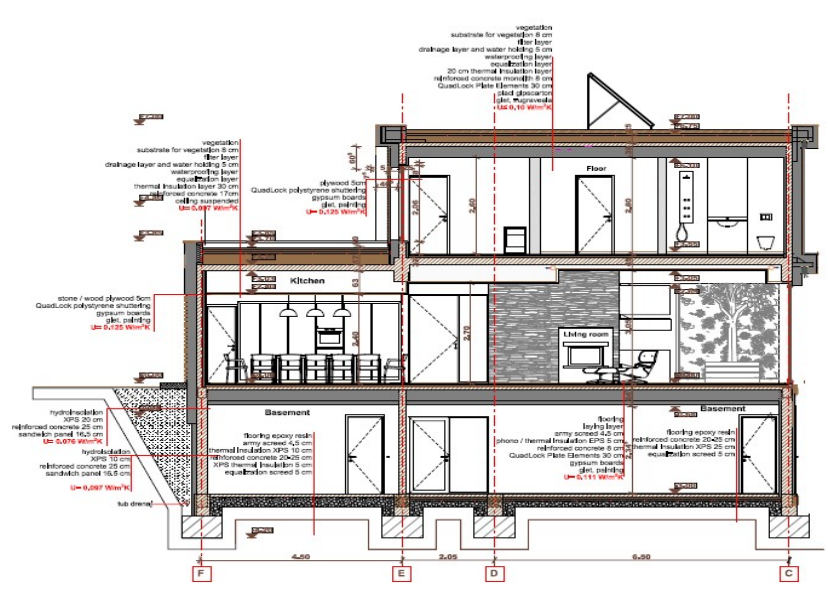

Fig. 1. Vertical section of the building

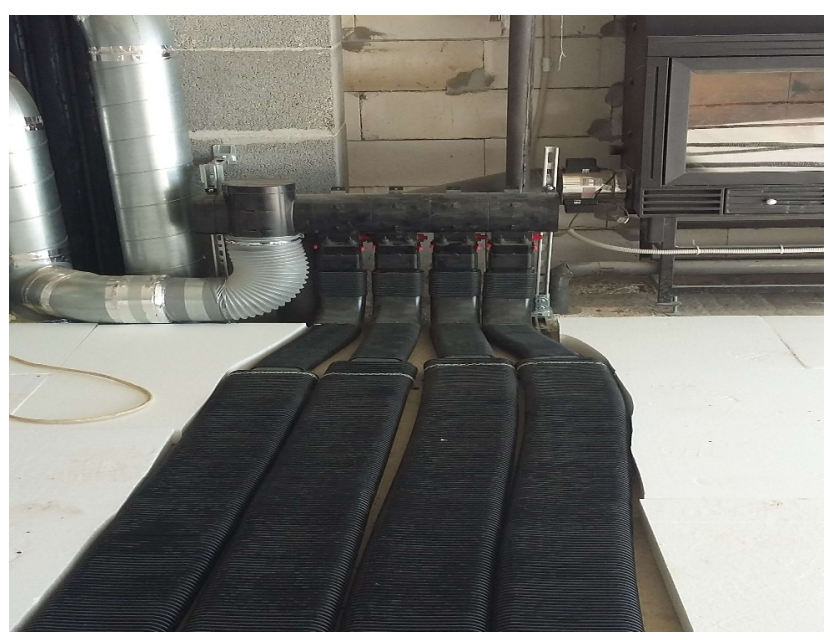

Fig. 2. The air distribution system configuration

The closed-loop air-to-air geothermal collector system consists of a horizontal serpentine made of a polyethylene pipe placed in the soil at a depth of about 4 meters.

The ventilation system consists of two rectangular fresh air inlets $(0.8 \times 0.15 \mathrm{~m})$ placed on the floor in the living room and six exhaust circular section air jets of $0.1 \mathrm{~m}$ diameter, arranged at the roof of the kitchen.

The ventilation system has the following characteristics, [10]:

- volume flow rate of air ventilation unit: $50-320 \mathrm{~m}^{3} / \mathrm{h}$,

- recovery rate - heat exchanger: $84 \%$,

- electricity demand: $0.31 \mathrm{Wh} / \mathrm{m}^{3}$,

- noise level: $28 \mathrm{~dB}(\mathrm{~A})$.

\subsection{Computation domain}

In order to facilitate the operation of the application, the area of interest/calculation, presented in the Figure 3, located on the ground floor of the building, representing the simulation field, was selected from the passive house architecture plan. The volume of the simulation domain analyzed is $271 \mathrm{~m}^{3}$.

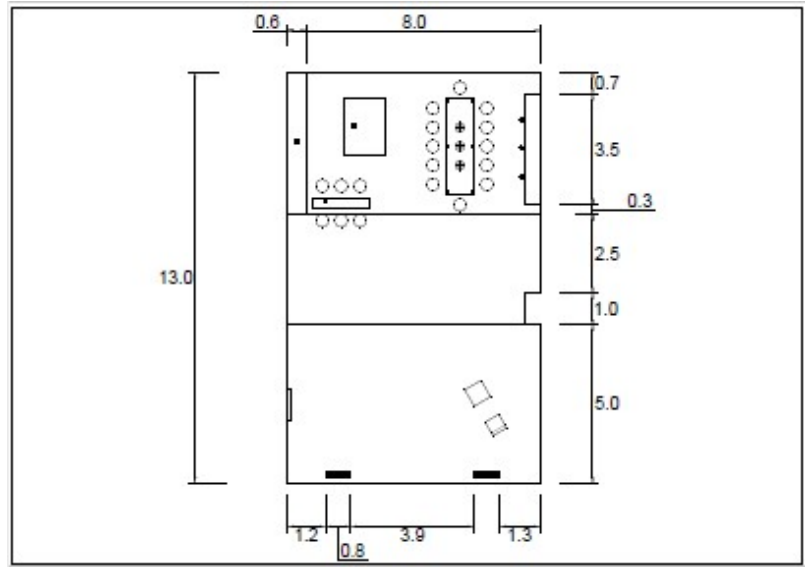

Fig. 3. The domain of simulation $-2 \mathrm{D}$ view 
The working agent in the field of simulation/calculation, was chosen the dry air, whose thermo-physical properties were selected from the program database, with the following values, [11]:

- temperature, $\mathrm{T}_{20}=293.15 \mathrm{~K}$,

- density, $\rho_{\text {air }}=1.205 \mathrm{~kg} / \mathrm{m}^{3}$,

- kinematic viscosity, $v_{20}=15.1 \cdot 10^{-6} \mathrm{~m}^{2} / \mathrm{s}$,

- dynamic viscosity, $\eta_{20}=18.12 \cdot 10^{-6} \mathrm{~N} \cdot \mathrm{s} / \mathrm{m}^{2}$,

- pressure, $\mathrm{p}=101325 \mathrm{~N} / \mathrm{m}^{2}$.

\subsection{Conditions of uniqueness}

The second step was to set boundary conditions as follows:

- NO SLIP, the layer of air that comes into contact with the wall surface is adherent to it, $\left(\mathrm{v}_{0}=0 \mathrm{~m} / \mathrm{s}\right)$

- balanced ventilation, $\mathrm{V}_{\mathrm{i}}=\mathrm{V}_{\mathrm{e}}$,

- open boundary for outlet grilles

For this study, respecting the required minimum ventilation flow rate for different levels of occupancy of the simulation domain, we simulated three cases, all of them having the boundary conditions as uniform velocity inlets:

- case 1: $\mathrm{v}_{1}=0.1 \mathrm{~m} / \mathrm{s}, \mathrm{V}_{1}=86 \mathrm{~m}^{3} / \mathrm{h}$, no person,

- case $2: \mathrm{v}_{2}=0.2 \mathrm{~m} / \mathrm{s}, \mathrm{V}_{2}=172 \mathrm{~m}^{3} / \mathrm{h}$, three persons,

- case $3: \mathrm{v}_{3}=0.5 \mathrm{~m} / \mathrm{s}, \mathrm{V}_{3}=215 \mathrm{~m}^{3} / \mathrm{h}$, four persons.

\subsection{Simulation of model}

Defining the geometry of the simulated models was based on the data taken from the field and the architectural design of the passive house using the Autocad 3D module, shown in Figures 4.

Respecting the design and execution data, the fresh air and exhaust air entrainment grids were placed as follows:

- inlet grilles for introducing fresh air into the flooring layer of the living room at a distance of $30 \mathrm{~cm}$ from the wall, the wall disposed on the south side of the building;

- the exhaust air grilles in the kitchen ceiling, three above the food preparation equipment (stove / electric hob) in order to eliminate significant $\mathrm{CO}_{2}$ emissions, and high humidity in the area of the dishwashers and three behind the serving area of the meal.

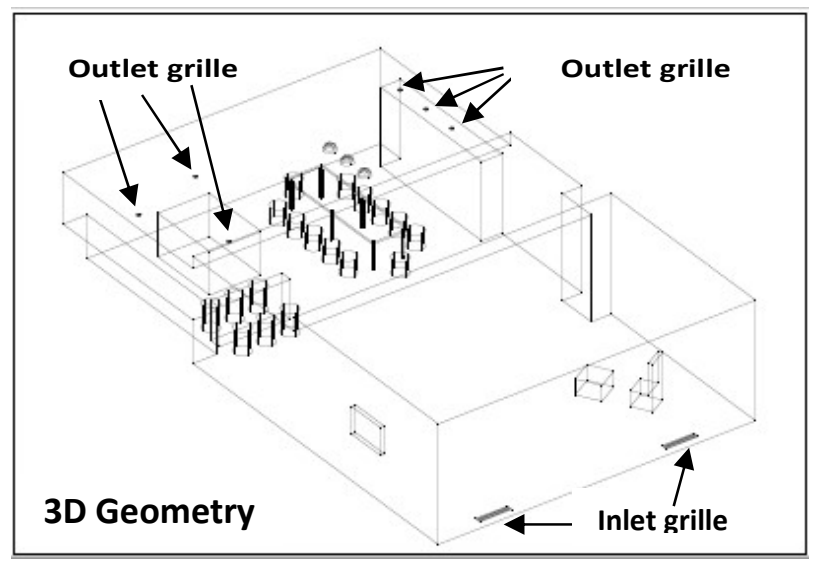

Fig. 4. Simulation of model - 3D view

\subsection{Mesh generating}

Numerical modeling and numerical simulation of airflow behavior through the computational domain was performed using specialized commercial software COMSOL MULTYPHISICS, version 3.5a.

This software application provides easy to use interfaces, algorithms and effective solution. It can fully control the generation nodal networks providing a development environment and complete computing for modeling coupled physical processes described by differential equation [12].

In the numerical simulation, for the purpose of defining the configuration of the node network and for the purpose of analyzing the flow field of the working fluid through the simulation domain, the k- $\varepsilon$ turbulence module was used, based on the Navier-Stokes motion equation (1):

$$
\rho \frac{\partial \mathbf{u}}{\partial \mathbf{t}}-\eta \nabla^{2} \mathbf{u}+\rho(\mathbf{u} * \nabla) \mathbf{u}+\nabla_{\mathbf{p}}=\mathbf{F}, \nabla * \mathbf{u}=\mathbf{0}
$$

where $\eta$ - dynamic viscosity, $\mathrm{N} \cdot \mathrm{s} / \mathrm{m}^{2}, \rho$ - density, $\mathrm{kg} / \mathrm{m}^{3}$, $\mathrm{u}$ - speed, $\mathrm{m} / \mathrm{s}, \mathrm{p}$ - pressure, N/m², F - volumegravitational force, $\mathrm{N} / \mathrm{m}^{3}$.

Before computer simulation of fundamental governing the flow equations, the following simplifying hypotheses were established, [11]:

- stationary regime;

- Newtonian incompressible fluid (speeds, low pressures - no compressibility factor);

- isothermal jet, (the inlet air temperature is the same as the air inside) ;

- constant temperature;

- mass forces are neglected (there are no pressure differences determined by the gravitational field);

- adiabatic system (there is no heat transfer but just impulse);

- no internal heat sources.

For the mesh domain simulation, finite element method was adopted, whereby the whole virtual field was divided into a finite number of elements, sub-areas of variable size and shape which are interconnected by a discrete number of nodes.

Analyzing the result of the meshing, we note that the mode of division of the simulation domain is uneven, the finite elements of the nodal network being in the form of linear tetrahedral. These present a greater density of nodal network elements near the bounded areas of the simulation domain, as shown in Figures 5a, 5b, 5c and 5b, obtaining a total 34497 finite elements.

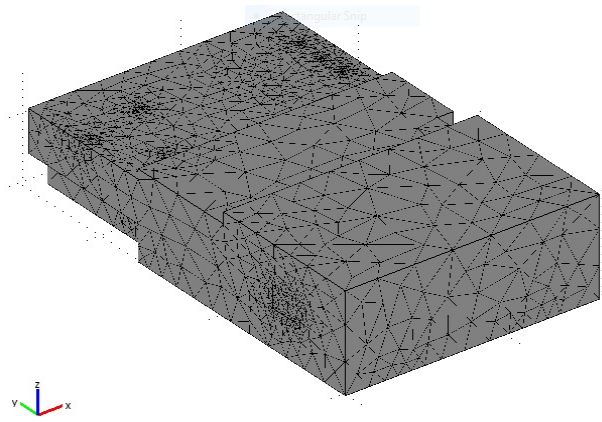

Fig. 5a. Mesh-3D general view 


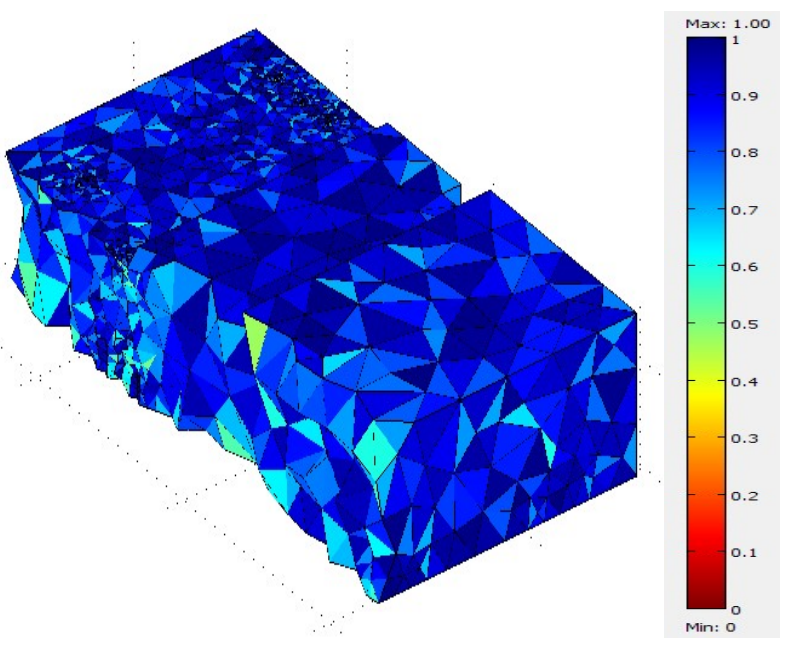

Fig. 5b. Mesh - yz section plan - 3D view

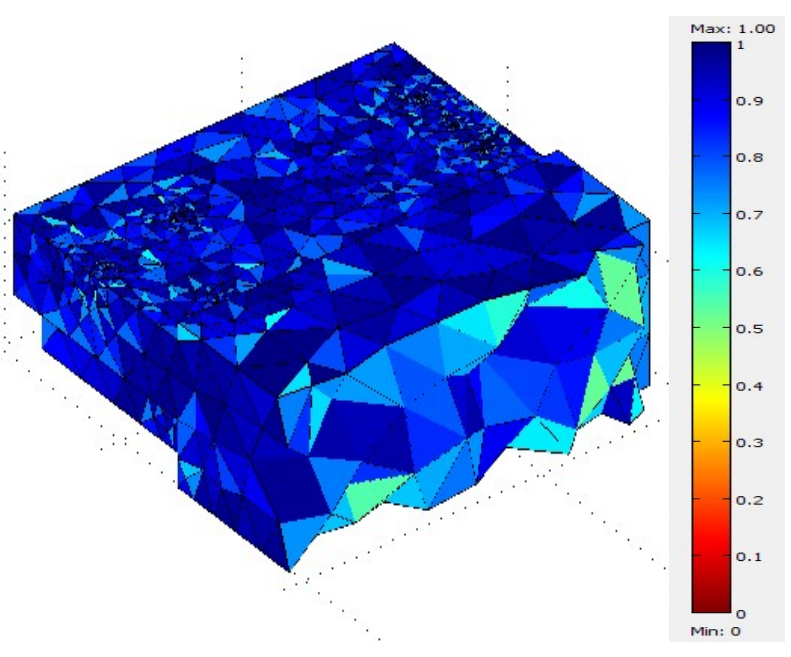

Fig. 5c. Mesh - xz section plan - 3D view

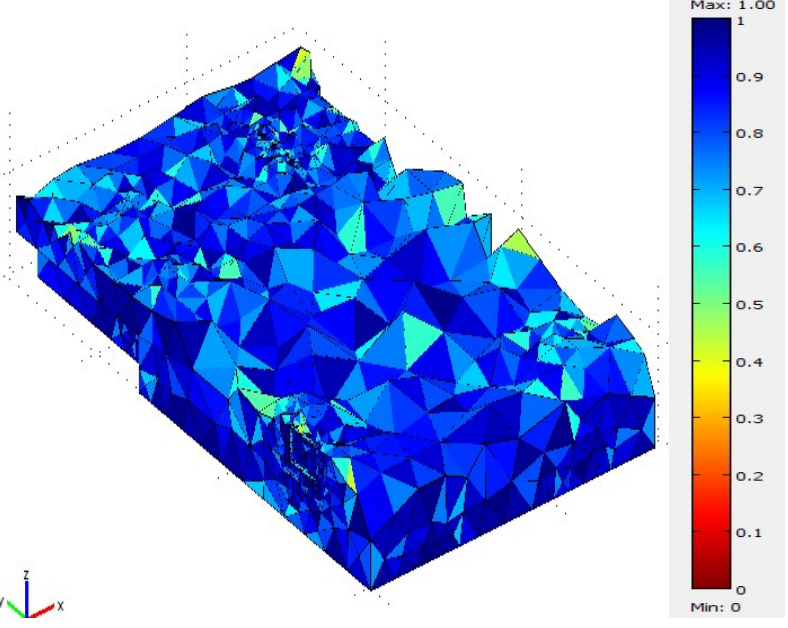

Fig. 5d. Mesh - xy section plan - 3D view

\subsection{Thermal comfort (PMV and PPD)}

Thermal comfort analysis was done for a useful plan specific to dining in the kitchen, by analytical determination and interpretation using PMV (Predicted mean vote) and PPD (Predicted percentage dissatisfied) thermal comfort indices. Preliminary determinations, the main basic parameters of calculation have been established:

- indoor air temperature, $\mathrm{t}_{\mathrm{a}}=20^{\circ} \mathrm{C}$,

- average radiation temperature, $\mathrm{t}_{\mathrm{r}}=20^{\circ} \mathrm{C}$,

- relative humidity of the indoor air, $\varphi_{\mathrm{a}}=50 \%$,

- water vapour partial pressure, $\mathrm{p}_{\mathrm{a}}=1168 \mathrm{~Pa}$,

- thermal resistance of the chlotes, $I_{\mathrm{cl}}=1 \mathrm{clo}$,

- metabolic rate, $M=1,2$ met,

- no effective mechanical power $\left(\mathrm{W} / \mathrm{m}^{2}\right), W=0$.

Due to the very low heat losses due to the thermal performance of the building components and the ventilation system, discomforts local thermal effects were not taken into account.

In accordance with the provisions and recommendations of the standard EN ISO 7730: 2005, [13], we start with an iterative calculation which determines successive: the temperature at the surface of the clothing, $t_{\mathrm{cl}}\left[{ }^{\circ} \mathrm{C}\right]$, the convective heat transfer coefficient $h_{c}\left[\mathrm{~W} /\left(\mathrm{m}^{2} \mathrm{~K}\right)\right]$, then calculating the clothing surface area factor $f_{c l}$, and finaly determining the PMV and PPD indices, using equations (2) and (3):

$$
\begin{aligned}
& P M V=[0,303 \cdot \exp (-0,036 \cdot M)+0,028] . \\
& \left\{\begin{array}{l}
(M-W)-3,05 \cdot 10^{-3} \cdot\left[5733-6,99 \cdot(M-W)-p_{\mathrm{a}}\right]-0,42 \cdot[(M-W)-58,15] \\
-1,7 \cdot 10^{-5} \cdot M \cdot\left(5867-p_{\mathrm{a}}\right)-0,0014 \cdot M \cdot\left(34-t_{\mathrm{a}}\right) \\
-3,96 \cdot 10^{-8} \cdot f_{\mathrm{cl}} \cdot\left[\left(t_{\mathrm{cl}}+273\right)^{4}-\left(\bar{t}_{\mathrm{r}}+273\right)^{4}\right]-f_{\mathrm{cl}} \cdot h_{\mathrm{c}} \cdot\left(t_{\mathrm{cl}}-t_{\mathrm{a}}\right)
\end{array}\right\} \\
& P P D=100-95 \cdot \exp \left(-0,03353 \cdot P M V^{4}-0,2179 \cdot P M V^{2}\right)
\end{aligned}
$$

\section{Results and discussions}

Local analysis of the air flow behavior near the exit section of the inlet grids and the inlet of the extraction grids, respectively, by computerized simulation of the flow of the working fluid through the simulation range for the three reference instances of the input speed of: $0.1,0.2$ and $0.5 \mathrm{~m} / \mathrm{s}$ was performed as:

- quantitative: by the velocity contours;

- qualitative: by the current lines and velocity vectors.

A local quantitative analysis way of working fluid flow through the simulation is carried out by means of the contours of the velocity distribution, being two vertical reference planes corresponding to the fresh air intake grilles and the evacuation of the vicious air.

The distribution of the velocity contours in the conditions of the three fresh air intake velocities in the vertical plane corresponding to the input grids is shown in Figures: 6, 6a, 6b and 6c. 


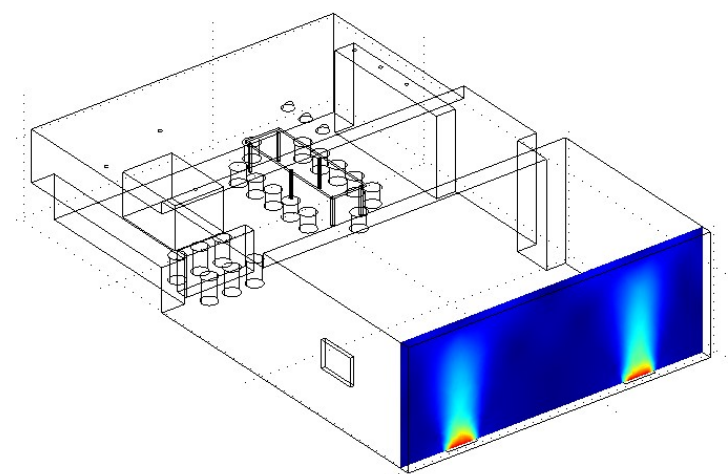

Fig. 6. Distribution of the velocity contours, inlet grilles, $3 \mathrm{D}$ general view

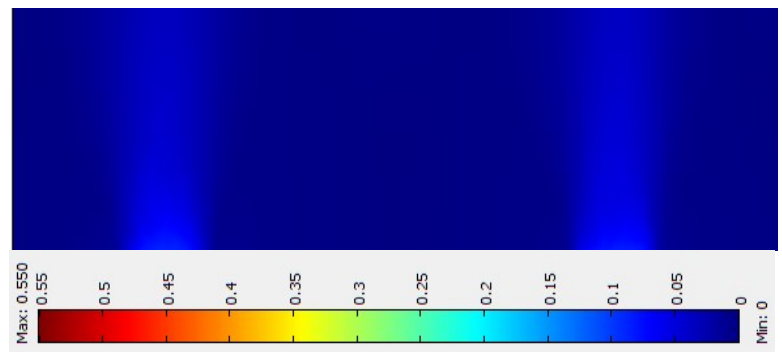

Fig. 6a. Distribution of the velocity contours, inlet grilles: Case 1: $\left(\mathrm{v}_{1}=0,1 \mathrm{~m} / \mathrm{s}, \mathrm{V}_{1}=86 \mathrm{~m} 3 / \mathrm{h}\right)$

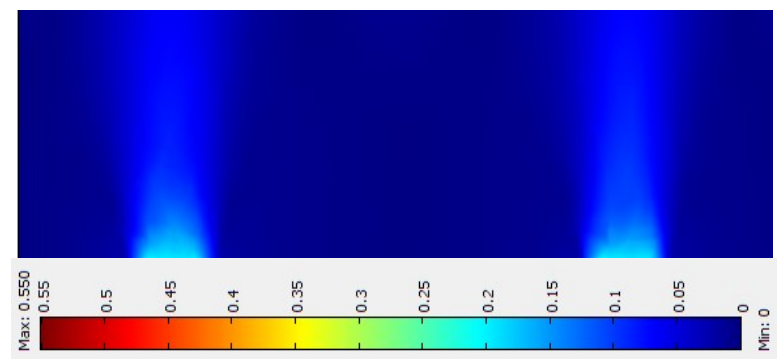

Fig. 6b. Distribution of the velocity contours, inlet grilles Case 2: $\left(\mathrm{v}_{2}=0,2 \mathrm{~m} / \mathrm{s}, \mathrm{V}_{2}=172 \mathrm{~m}^{3} / \mathrm{h}\right)$

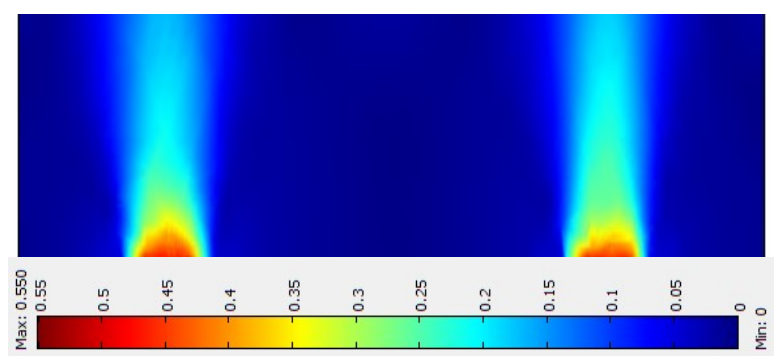

Fig. 6c. Distribution of the velocity contours, inlet grilles: Case 3: $\left(\mathrm{v}_{3}=0,5 \mathrm{~m} / \mathrm{s}, \mathrm{V}_{3}=215 \mathrm{~m}^{3} / \mathrm{h}\right)$

In the figures $6 a, 6 b, 6 c$, it can be observed that, when the fresh air flows from the input grids, the distribution of air velocity contours in the reference vertical plane gives rise to a spectral definition which intensifies with the increase of the introduction velocity.

In the case of the exhaust air grilles, the distribution of the gear contours which arises under the conditions of the three fresh air intake speeds, in the vertical plane corresponding to the exhaust grilles, is shown in Figures 7, $7 \mathrm{a}, 7 \mathrm{~b}$ and $7 \mathrm{c}$.

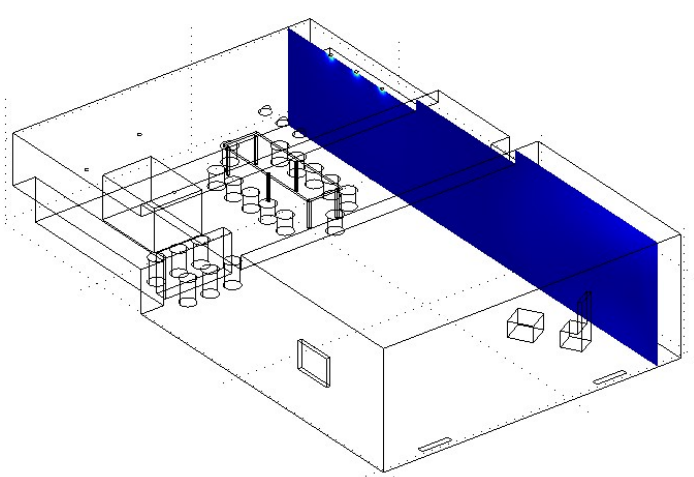

Fig. 7. Distribution of the velocity contours, outlet grilles, 3D general view

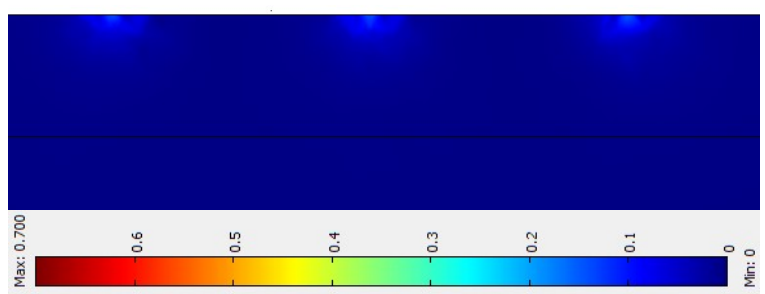

Fig. 7a. Distribution of the velocity contours, outlet grilles, Case 1: $\left(\mathrm{v}_{1}=0,1 \mathrm{~m} / \mathrm{s}, \mathrm{V}_{1}=86 \mathrm{~m} 3 / \mathrm{h}\right)$

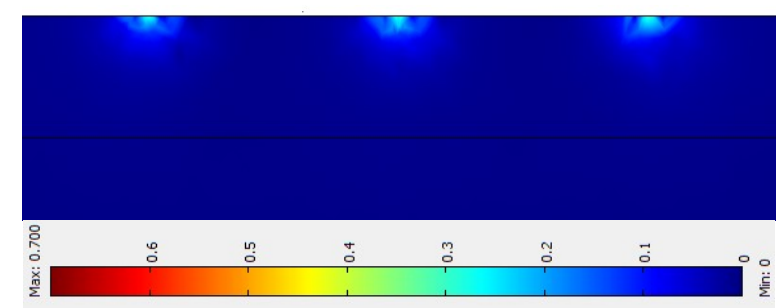

Fig. 7b. Distribution of the velocity contours, outlet grilles, Case 2: $\left(\mathrm{v}_{2}=0,2 \mathrm{~m} / \mathrm{s}, \mathrm{V}_{2}=172 \mathrm{~m}^{3} / \mathrm{h}\right)$

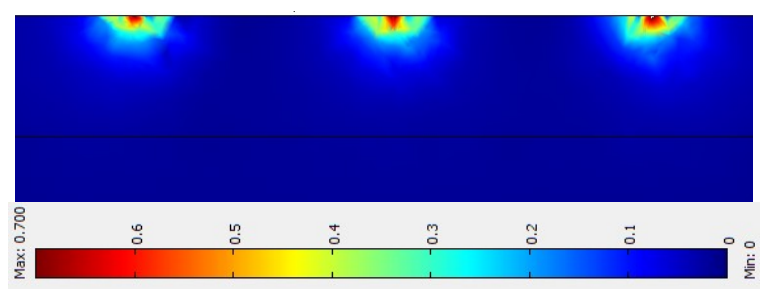

Fig. 7c. Distribution of the velocity contours, outlet grilles, Case 3: $\left(\mathrm{v}_{3}=0,5 \mathrm{~m} / \mathrm{s}, \mathrm{V}_{3}=215 \mathrm{~m}^{3} / \mathrm{h}\right)$

In these cases, it is ascertained that, with the increase of the fresh air introduction speed, a small variation of the speed contours at the exhaust grilles of the air is observed.

The qualitative analysis of the local distribution at the level of fresh air inlet grilles evidenced by the distribution of the current lines is shown in Figures 8a, $8 \mathrm{~b}$ and $8 \mathrm{c}$. 


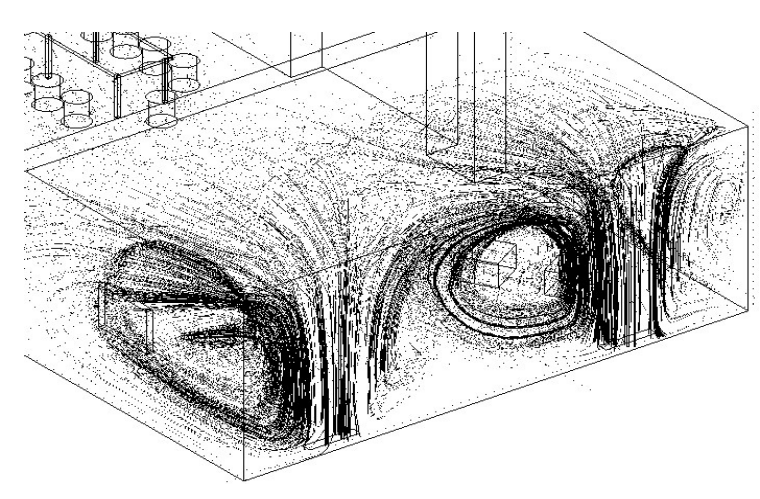

Fig. 8a. Distribution of current lines at inlet grilles, Case 1: $\left(\mathrm{v}_{1}=0,1 \mathrm{~m} / \mathrm{s}, \mathrm{V}_{1}=86 \mathrm{~m}^{3} / \mathrm{h}\right)$

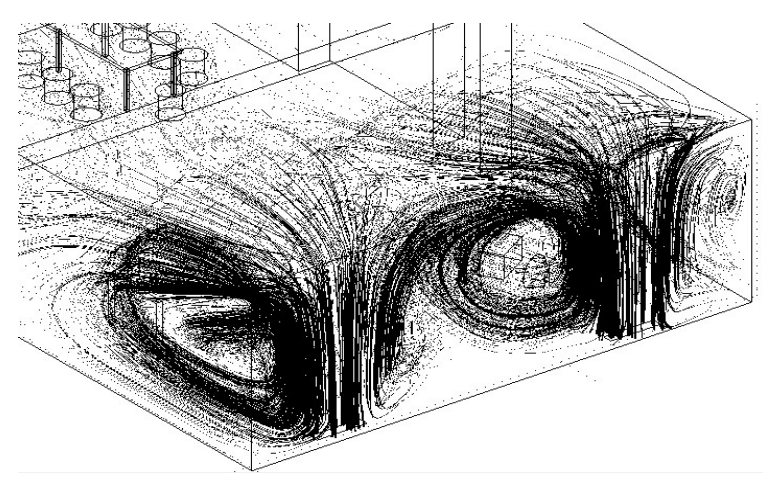

Fig. 8b. Distribution of current lines at inlet grilles, Case 2: $\left(\mathrm{v}_{2}=0,2 \mathrm{~m} / \mathrm{s}, \mathrm{V}_{2}=172 \mathrm{~m}^{3} / \mathrm{h}\right)$

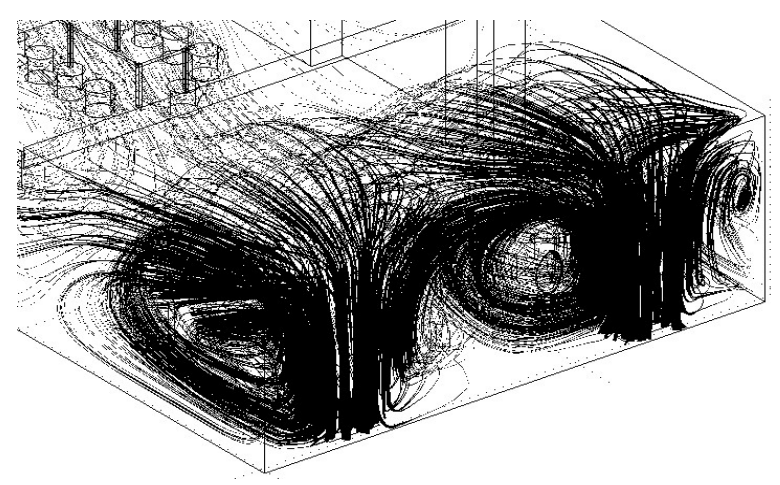

Fig. 8c. Distribution of current lines at inlet grilles Case 3: $\left(\mathrm{v}_{3}=0,5 \mathrm{~m} / \mathrm{s}, \mathrm{V}_{3}=215 \mathrm{~m}^{3} / \mathrm{h}\right)$

When the fresh air leaving the area grids introducing next to their arises a turbulent movement of the working fluid, whose intensity increases with increasing speed of its introduction.

The qualitative analysis of the local distribution of the air currents in the vicinity of the exhaust grilles revealed by the distribution of the current lines is shown in Figures: 9a, 9b and 9c.

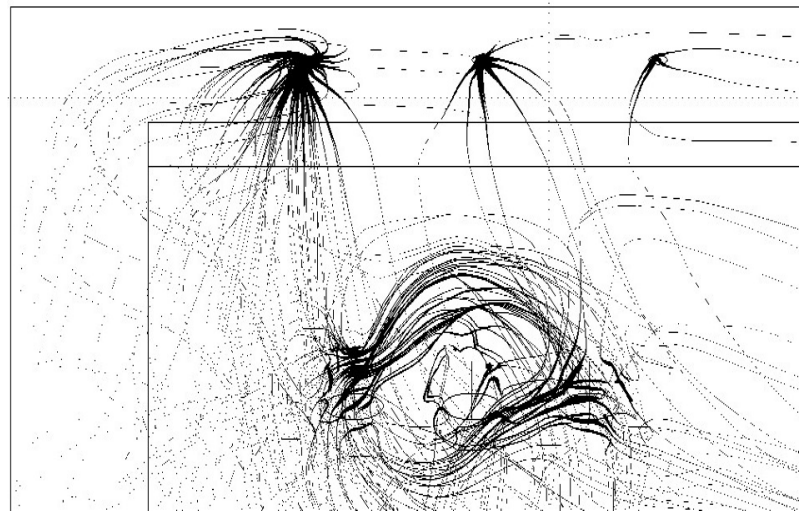

Fig. 9a. Distribution of current lines at outlet grilles Case 1: $\left(\mathrm{v}_{1}=0,1 \mathrm{~m} / \mathrm{s}, \mathrm{V}_{1}=86 \mathrm{~m}^{3} / \mathrm{h}\right)$

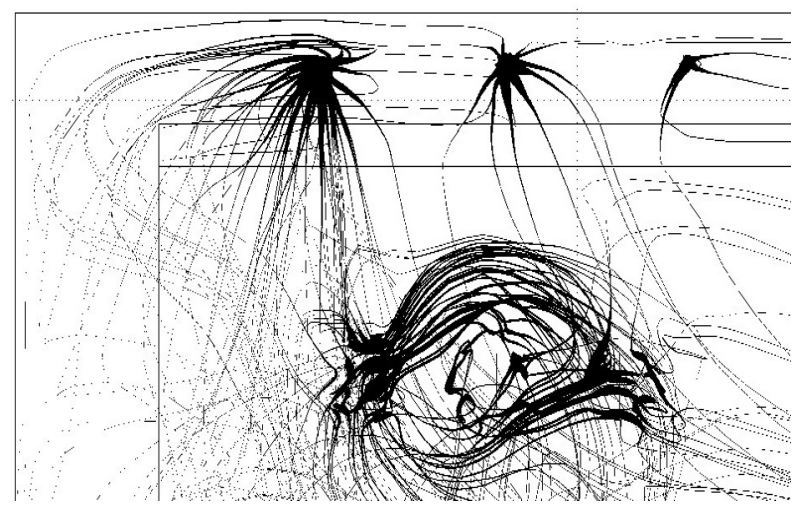

Fig. 9b. Distribution of current lines at outlet grilles Case 2: $\left(\mathrm{v}_{2}=0,2 \mathrm{~m} / \mathrm{s}, \mathrm{V}_{2}=172 \mathrm{~m}^{3} / \mathrm{h}\right)$

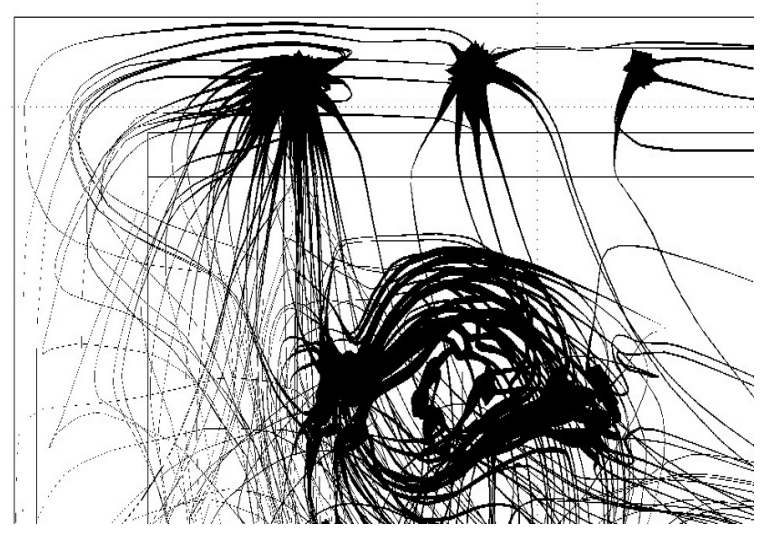

Fig. 9c. Distribution of current lines at outlet grilles Case 3: $\left(\mathrm{v} 3=0,5 \mathrm{~m} / \mathrm{s}, \mathrm{V}_{3}=215 \mathrm{~m}^{3} / \mathrm{h}\right)$

In the area near the inlet section of the exhaust air grilles located above the table serving area, the distribution of the current lines is uneven, their density being different.

At the same time, at the ceiling level in the upper area, the space above the kitchen table gives rise to an area where the air is recycled.

Another way of qualitative assessment of the local distribution of the working fluid in adjacent grids of fresh air input is performed by the velocity vector distribution shown in Figures 10a, 10b and 10c. 


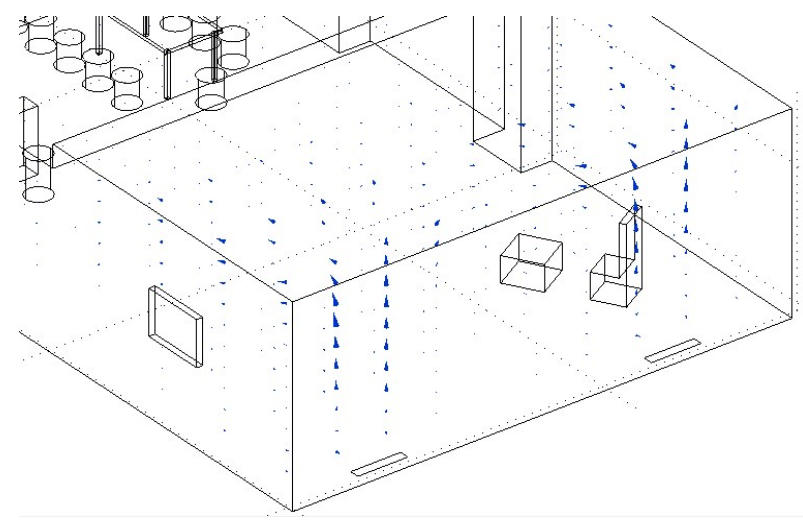

Fig. 10a. Distribution of the velocity vectors, inlet grilles, Case 1: $\left(\mathrm{v}_{1}=0,1 \mathrm{~m} / \mathrm{s}, \mathrm{V}_{1}=86 \mathrm{~m} 3 / \mathrm{h}\right)$

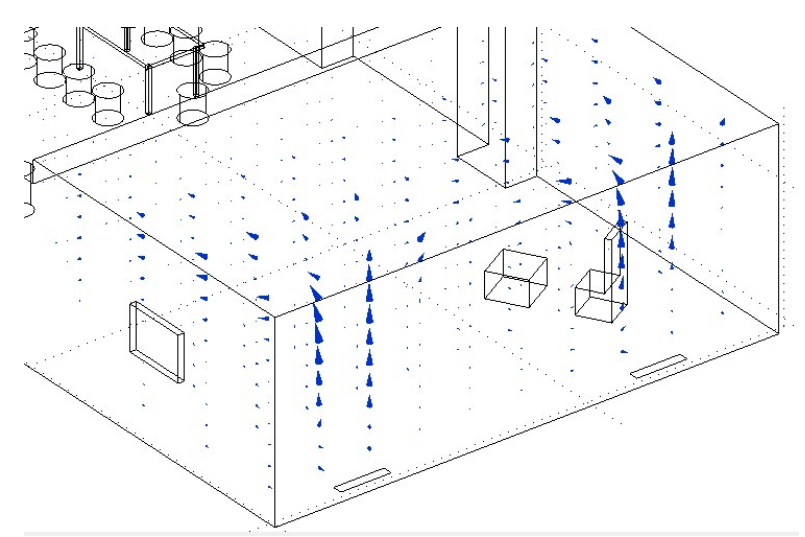

Fig. 10b. Distribution of the velocity vectors, inlet grilles, Case 2: $\left(\mathrm{v}_{2}=0,2 \mathrm{~m} / \mathrm{s}, \mathrm{V}_{2}=172 \mathrm{~m}^{3} / \mathrm{h}\right)$

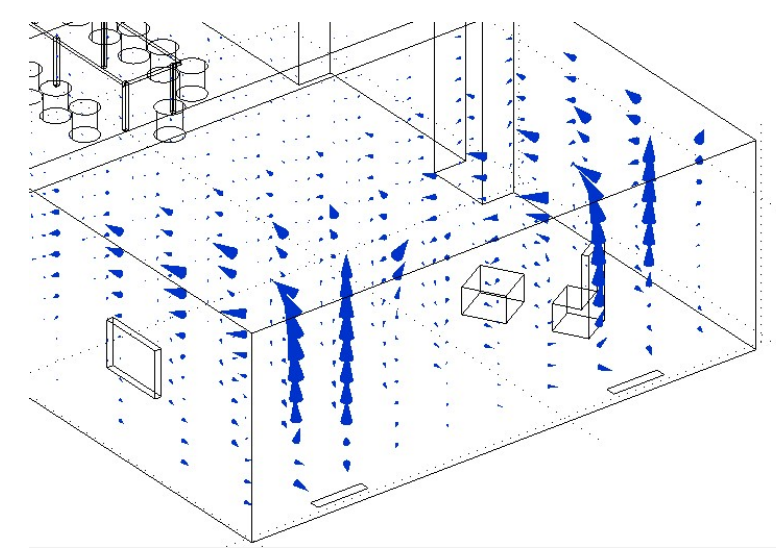

Fig. 10c. Distribution of the velocity vectors, inlet grilles Case 3: $\left(\mathrm{v}_{3}=0,5 \mathrm{~m} / \mathrm{s}, \mathrm{V}_{3}=215 \mathrm{~m}^{3} / \mathrm{h}\right)$

It is noted that in the vicinity of the input grids, the velocity vectors become more visible as the fresh air intake speed increases, occupying the entire area under analysis.

The exhaust air flow distribution in the adjacent section inlet outlet grilles are shown in the Figures: 11a, $11 \mathrm{~b}$ and $11 \mathrm{c}$.

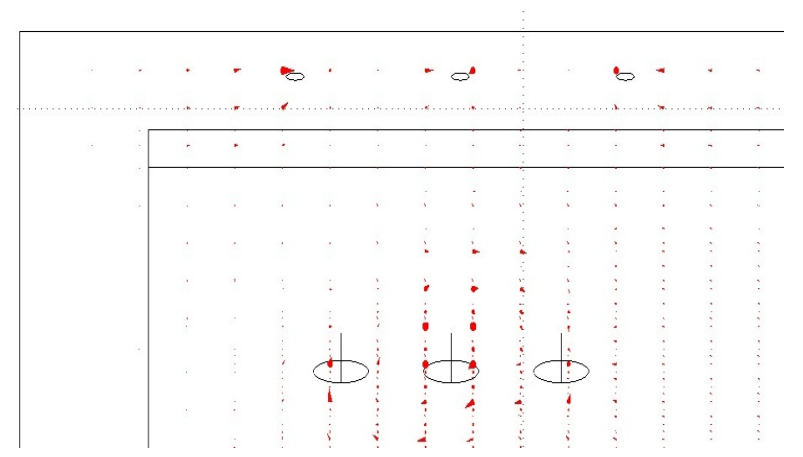

Fig. 11a. Distribution of the velocity vectors, outlet grilles Case 1: $\left(\mathrm{v}_{1}=0,1 \mathrm{~m} / \mathrm{s}, \mathrm{V}_{1}=86 \mathrm{~m} 3 / \mathrm{h}\right)$

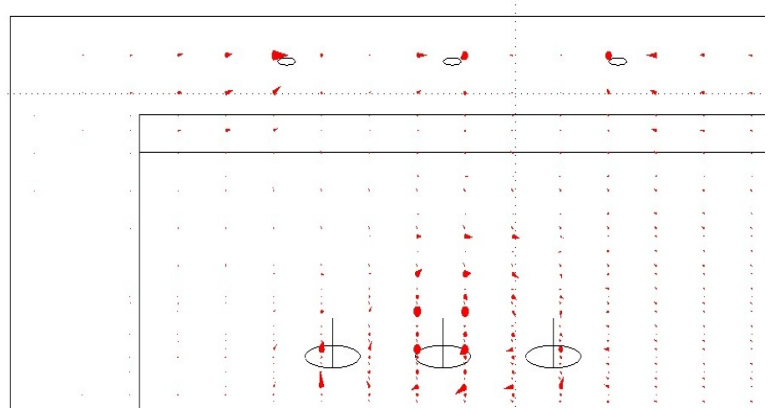

Fig. 11b. Distribution of the velocity vectors, outlet grilles Case 2: $\left(\mathrm{v}_{2}=0,2 \mathrm{~m} / \mathrm{s}, \mathrm{V}_{2}=172 \mathrm{~m}^{3} / \mathrm{h}\right)$

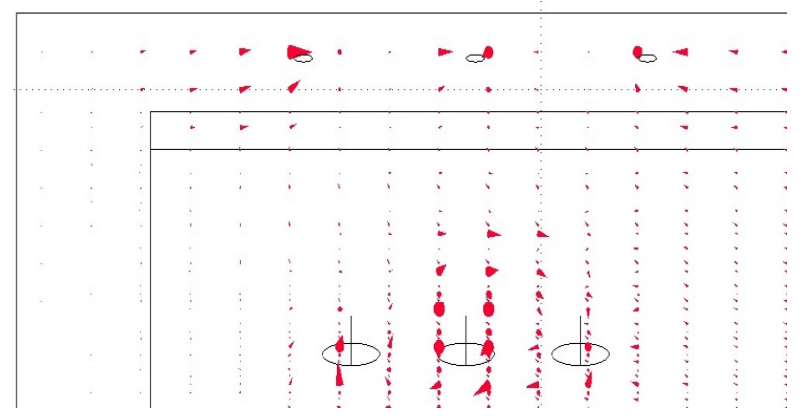

Fig. 11c. Distribution of the velocity vectors, outlet grilles Case 3: $\left(\mathrm{v}_{3}=0,5 \mathrm{~m} / \mathrm{s}, \mathrm{V}_{3}=215 \mathrm{~m}^{3} / \mathrm{h}\right)$

In this case, the speed profiles in the field of exhaust grille located above the kitchen furniture are distinguished by their high density of the velocity vector in the case of grid located near the wall. The velocity vector distribution varies proportionally to the increase in fresh air intake speed.

The overall determination of the PMV and PPD values presented in Table 1 was performed using average values of the air velocities $\left(\mathrm{v}_{\mathrm{ar}}\right)$ in the simulation field, calculated by integrating the velocity field over the entire volume of the simulation domain $\left(\mathrm{V}_{\mathrm{sd}}\right)$ by means of the COMSOL Multiphysics application. 
Table 1. Determination of PMV and PPD indexes

\begin{tabular}{|c|c|c|c|c|}
\hline Case studied & $\begin{array}{c}\mathrm{V}_{\mathrm{sd}} \\
{\left[\mathrm{m}^{3}\right]}\end{array}$ & $\begin{array}{c}\mathrm{V}_{\mathrm{ar}} \\
{[\mathrm{m} / \mathrm{s}]}\end{array}$ & $\begin{array}{c}\text { PMV } \\
{[-]}\end{array}$ & $\begin{array}{c}\text { PPD } \\
{[\%]}\end{array}$ \\
\hline $\begin{array}{c}\mathrm{v}_{1}=0,1 \mathrm{~m} / \mathrm{s} \\
\mathrm{V}_{1}=86 \mathrm{~m} 3 / \mathrm{h} \\
\text { no person }\end{array}$ & & 0.0028 & -0.3149 & 7.061 \\
\hline $\begin{array}{c}\mathrm{V}_{2}=0,2 \mathrm{~m} / \mathrm{s} \\
\mathrm{V}_{2}=172 \mathrm{~m}^{3} / \mathrm{h} \\
3 \text { persons }\end{array}$ & 271 & 0.0056 & -0.3149 & 7.061 \\
\hline $\begin{array}{c}\mathrm{v}_{3}=0,5 \mathrm{~m} / \mathrm{s} \\
\mathrm{V}_{3}=215 \mathrm{~m}^{3} / \mathrm{h} \\
4 \text { persons }\end{array}$ & & 0.0140 & -0.3149 & 7.061 \\
\hline
\end{tabular}

Analyzing the values of the PMV index in Table 1 it can be observed that according to the provisions of standard EN ISO7730:2005 they are in the neutral range and we can appreciate that the thermal equilibrium of the occupants or thermal comfort, given by the thermal comfort sensation is assured.

In the case of the PPD index it can be seen that the value obtained is in the same value range as for the PMV, which is why it can be appreciated that for the occupants of the useful space we have the condition of thermal comfort.

The analysis of the PMV and PPD index values shows that the analyzed microclimate is in accordance with the assessment criteria of EN ISO 7730: 2005 in thermal comfort category $\mathrm{B}(-0,5<\mathrm{PMV}<0,5$, PPD $<10 \%)$.

\section{Conclusions}

The local analysis of the flow of air currents near the air inlet and outlet grilles was achieved by qualitative assessment of their distribution by means of current lines and velocity and quantity vectors by means of gear contours.

The analysis revealed that both the distribution of turbulent air currents in the fresh air inlet grilles area and their behavior within the recirculation zones do not create discomfort zones and do not affect the thermal comfort of the occupants.

Due to the very close values of the average velocities of the air currents in the simulation field, in the three studied cases, following the determination of the PMV and PPD indexes, identical values were obtained.

This leads to the fact that the change of the fresh air input value does not influence the average speed of the air currents through the simulation range and does not change the occupant thermal comfort.

\section{Acknowledgement}

This work was partially supported by the internal grant of the Doctoral School of the Technical University of Civil Engineering of Bucharest GID-2018.

\section{References}

1. $* * *$, Passive-On Project. Design guidelines. Policy mechanism, www.passive-on.org/en

2. $* * *$, Pass-net Project, www.pass-net.net/index.htm

3. ***, PassREg Project, Passive House Regions with Renewable Energies, www.passreg.eu

4. ***, Passipedia - The Passive House Resource, www.passipedia.org

5. J. Wallin, H. Madani, J. Claesson, Run-around coil ventilation heat recovery system: a comparative study between different system configurations. Applied Energy, 90 (2012)

6. P.M. Cuce, S. Riffat, A comprehensive review of heat recovery systems for building applications. Renewable and Sustainable Energy Reviews, 47 (2015)

7. G.Gaëlle, M. H. Sherman, I. S. Walker, Smart ventilation energy and indoor air quality performance in residential buildings: A review Energy and Buildings, 165 (2018)

8. A. Flaga-Maryanczyk, J. Schnotale, J. Radon, K. Was, Experimental measurements and CFD simulation of a ground source heat exchanger operating at a cold climate for a passive house ventilation system. Energy Building, 68 (2014)

9. ***, COMSOL Multiphysics - User's Guide, (2006)

10. ***, Pluggit - The residential ventilation, www.pluggit.com

11. D.D. Sabie, A.-G. Ghiaus, Influence of furniture arrangement on airflow distribution in open concept passive houses, E3S Web of Conferences, $\mathbf{8 5}$, (2018)

12. ***, Understand, Predict, and Optimize PhysicsBased Designs and Processes, www.comsol.com/comsol-multiphysics

13. ***, EVS- EN ISO 7730 Ergonomics of the thermal environment - Analytical determination and interpretation of thermal comfort using calculation of the PMV and PPD indices and local thermal comfort criteria, (2005). 